\title{
Emissions from Ethanol- and LPG-Fueled Vehicles
}

\author{
Mark E. Pitstick
}

\section{Center for Transportation Research}

\author{
Argonne National Laboratory
}

9700 South Cass Avenue

Argonne, Illinois 60439

For Publication in the

Transportation Research Record

\section{DISCLAIMER}

This report was prepared as an account of work sponsored by an agency of the United States Government. Neither the United States Government nor any agency thereof, nor any of their employees, makes any warranty, express or implied, or assumes any legal liability or responsibility for the accuracy, completeness, or usefulness of any information, apparatus, product, or process disclosed, or represents that its use would not infringe privately owned rights. Reference herein to any specific commercial product, process, or service by trade name, trademark, manufacturer, or otherwise does not necessarily constitute or imply its endorsement, recommendation, or favoring by the United States Government or any agency thereof. The views and opinions of authors expressed herein do not necessarily state or reflect those of the United States Government or any agency thereof. 


\section{DISCLAIMER}

Portions of this document may be illegible in electronic image products. Images are produced from the best available original document. 


\title{
Emissions from Ethanol- and LPG-Fueled Vehicles
}

\author{
by \\ Mark E. Pitstick \\ Center for Transportation Research \\ Argonne National Laboratory \\ 9700 South Cass Avenue \\ Argonne, Illinois 60439
}

\section{ABSTRACT}

This paper addresses the environmental concerns of using neat ethanol and liquified petroleum gas (LPG) as transportation fuels in the United States. Low-level blends of ethanol (10\%) with gasoline have been used as fuels in the United States for more than a decade, but neat ethanol (85\% or more) has only been used extensively in Brazil. LPG, which consists mostly of propane, is already used extensively as a vehicle fuel in the United States, but its use has been limited primarily to converted fleet vehicles. Increasing U.S. interest in alternative fuels has raised the possibility of introducing neat-ethanol vehicles into the market and expanding the number of LPG vehicles. Use of such vehicles, and increased production and consumption of fuel ethanol and LPG, will undoubtedly have environmental impacts. If the impacts are determined to be severe, they could act as barriers to the introduction of neat-ethanol and LPG vehicles. Environmental concerns include exhaust and evaporative emissions and their impact on ozone formation and global warming, toxic emissions from fuel combustion and evaporation, and agricultural impacts from production of ethanol. The paper is not intended to be judgmental regarding the overall attractiveness of ethanol or LPG as compared with other transportation fuels. The environmental concerns are reviewed and 
summarized, but the only conclusion reached is that there is no single concern that is likely to prevent the introduction of neat-ethanol-fueled vehicles or the increase in LPG-fueled vehicles.

\section{INTRODUCTION}

Expanding U.S. interest in alternative fuels has prompted a more detailed look at ethanol and liquified petroleum gas (LPG), currently the two most widely used alternative transportation fuels in the United States and in the world. In the case of ethanol, the need for further analysis is in the area of neat fuel usage since E10 (10\% ethanol, $90 \%$ gasoline) is already used extensively without major recognized environmental, health, and safety impacts. In the case of LPG, further analysis is needed to address the possibility of expanded use outside of fleets.

Ethanol, also known as ethyl or grain alcohol, is usually produced by fermentation of such agricultural products as corn or sugar cane. Ethanol has a number of properties that make it attractive as a motor fuel. As shown in Table 1, the octane rating of ethanol is higher than that of gasoline, which together with other fuel properties means that vehicles can be designed for improved energy efficiency. The physical properties of pure ethanol make engine starting difficult in cold weather; this problem is overcome with the addition of gasoline. A mixture of $85 \%$ ethanol, $15 \%$ gasoline is called E85 and may be referred to as neat or near-neat. Technically the term neat is limited to pure ethanol (E100); thus, E85 should be called near-neat ethanol, but fuel ethanol rarely exists in pure form due to the presence of water, gasoline, and other components. Neat ethanol generally refers to any fuel that is at least $85 \%$ ethanol.

Ethanol has been used extensively in the United States since 1979 in the form of "gasohol" or E10 (10\% ethanol, 90\% gasoline). In fact, the United States currently produces almost one billion gallons of ethanol per year, about $90 \%$ of which comes from corn and is blended with gasoline (2). However, only a limited number of vehicles in the United States run on neat ethanol, and most of them are part of demonstration tests. 
Although government and industry in the United States have focused more attention on neat methanol (M85 and M100), ethanol has a proven track record as a neat fuel in Brazil, where nearly five million vehicles currently operate on 190-proof ethanol (95\% ethanol, 5\% water). Ethanol can be used as a primary vehicle fuel in either the neat (pure) or near-neat form. Certain modifications are required in spark-ignition vehicles, including engine-management changes and material changes in the fuel system. To take full advantage of ethanol's higher octane value, the compression ratio should also be increased. Because of ethanol's low cetane value, its use in compression-ignition engines requires either direct ignition or cetane enhancement. Because ethanol is a liquid fuel at standard temperatures and pressures, it can be incorporated into petroleum-distribution systems and vehicle-fuel systems with greater ease than alternative fuels that are gaseous under these conditions.

There are currently about 400,000 LPG vehicles operating in the United States and about four million operating worldwide. Other countries with large LPG fleets include the Netherlands, with about 750,000 vehicles; Italy, with over 500,000 vehicles; and Canada, with over 100,000 vehicles (3). Most LPG vehicles in the United States are converted gasoline vehicles, but Ford and Chrysler did provide original-equipment-manufacturer (OEM) light-duty vehicles to the Canadian market in the early 1980s, when LPG prices were low compared to gasoline (2). Recently, Ford announced the availability of medium-duty trucks that are specifically designed to operate on LPG. Also, Chrysler of Canada announced that they intend to develop and produce LPG-fueled light-duty trucks or vans by 1995 (4).

In the United States, the LPG used by vehicles consists primarily of propane (95\% or more), with the remainder composed of butane and other natural gas liquids (NGLs), including ethane. About $60 \%$ of LPG in the United States comes from natural gas processing plants, where propane and other NGLs are separated from natural gas. The remaining $40 \%$ of LPG is produced from crude oil as by-products during refinery processing (2). LPG is stored under pressure (about 200 psi) to keep the components in the liquid state at normal temperatures; thus, special tanks and fuel lines are required in the vehicle to store and deliver the pressurized fuel. LPG can be used in either dedicated or dual-fuel (LPG and gasoline) vehicles, but dual-fuel vehicles require separate 
fuel systems for each fuel. As with ethanol, LPG has a higher octane rating that allows higher compression ratios and greater efficiency in dedicated vehicles. Similarly, LPG vehicles require engine-management and fuel-system modifications, and LPG use in compression-ignition engines requires some form of ignition enhancement.

Increased use of alternative fuels will entail a variety of environmental, health, and safety concerns, because these fuels have different properties as compared with gasoline and diesel fuel. Environmental concerns include exhaust and evaporative emissions and their impact on ozone formation and global warming; toxic emissions from fuel combustion and evaporation; and agricultural impacts from the production of ethanol. Health concerns include fuel ingestion and toxicity, inhalation of toxic emissions, and spills and leaks. Safety concerns include flammability and fire hazards associated with the handling, transportation, and storage of the fuel. This paper does not address health and safety concerns but concentrates on environmental concerns associated with emissions from alternative-fueled vehicles that run on neat ethanol or LPG.

Combustion of ethanol and LPG will generate exhaust emissions of hydrocarbons (HC), carbon monoxide $(\mathrm{CO})$, nitrogen oxides $\left(\mathrm{NO}_{\mathrm{x}}\right)$, and toxic pollutants. In addition, evaporation and refueling will generate emissions of the fuel components. These emissions will react in the atmosphere and contribute to ozone formation, depending on their reactivity and the ambient conditions. Also, production and combustion of ethanol and LPG will generate carbon dioxide $\left(\mathrm{CO}_{2}\right)$ and other greenhouse gases that could contribute to global warming. Chang et al. (5) summarized the environmental concerns of ethanol- and LPG-fueled vehicles as compared with gasoline and diesel vehicles in a semiqualitative table that is reproduced, in part, in Table 2. Each of the concerns will be discussed in more detail below, and it should be noted that not all evaluations give results that agree with those listed in Table 2 .

\section{EXHAUST EMISSIONS}


The use of fuel ethanol and LPG in engines is likely to have a different impact on exhaust emissions depending on whether the engines use spark ignition or compression ignition. Table 3 gives the exhaust emission rates of ethanol and LPG spark ignition engines as compared with emission rates for similar vehicles and engines using methanol and gasoline. These results are discussed below, followed by a brief discussion of exhaust emissions from compression-ignition engines.

\section{Spark-Ignition Engines}

Because of ethanol's higher octane rating, the compression ratio of ethanol engines can be higher than that of gasoline engines, which results in greater fuel efficiency and power density. Ethanol's flame speed and other combustion properties also increase efficiency and power. The U.S. Environmental Protection Agency (EPA) estimates efficiency improvements of about $30 \%$ for neat ethanol (E100) in advanced dedicated vehicles, but only about $2.5 \%$ for near-neat ethanol (E85) in flexible fuel-vehicles (FFVs) (9). Conventional (contemporary) dedicated ethanol vehicles can achieve efficiency gains similar to methanol vehicles. Greater fuel efficiency partially makes up for the lower energy content of ethanol, which is only about $67 \%$ as much as gasoline on a volume basis, and leads to reductions in unburned fuel and lower HC exhaust emissions. Ethanol FFVs tested with the Federal Test Procedure (FTP) have demonstrated equivalent or lower HC exhaust emissions, as compared with gasoline, and dedicated ethanol vehicles are expected to be even better.

Formation of $\mathrm{NO}_{\mathbf{x}}$ could potentially be lower with ethanol than with gasoline, because the combustion temperature will be lower, and the water content of hydrous ethanol helps to limit $\mathrm{NO}_{\mathbf{X}}$ formation. However, the EPA sees no reason to expect or require ethanol vehicles to emit less $\mathrm{NO}_{\mathrm{x}}$ or $\mathrm{CO}$ from the tailpipe than gasoline vehicles with comparable control equipment, because there is an inherent trade-off between $\mathrm{NO}_{\mathrm{X}}$ reductions and reductions of $\mathrm{CO}$ and $\mathrm{HC}$ in vehicles using three-way catalysts (9). This trade-off applies to all fuels and occurs because $\mathrm{NO}_{\mathrm{X}}$ is reduced best by the catalyst under oxygen-poor conditions, while $\mathrm{CO}$ and $\mathrm{HC}$ are oxidized best under conditions 
of excess oxygen (10). The lean combustion capabilities of ethanol could decrease $\mathrm{CO}$ emissions and might allow a 1.0 gram per mile $\mathrm{NO}_{\mathrm{x}}$ standard to be met without a three-way catalyst, but future lower standards ( 0.4 gram per mile) will probably require catalysts, and thus, stoichiometric operation.

Hydrous ethanol, which consists of $95 \%$ ethanol and $5 \%$ water and is the result of distillation of a fermented liquid, must be denatured by adding poisonous or unpalatable ingredients in order to distinguish fuel ethanol from beverage ethanol for tax purposes. Gasoline is usually used as the denaturant, and hydrous ethanol mixed with 3-5\% gasoline has been used widely in Brazilian neat-ethanol vehicles.

Pure hydrous ethanol has a volatility that is too low to allow reliable starting with systems of the type used on gasoline vehicles. One method to overcome this problem is to use a separate supply of a different fuel to start and operate the engine until it is warm enough to run on ethanol. In Brazil, gasoline has been used for this method, but gaseous fuels could also be used. Compression-ignition engines could also be redesigned to include direct injection and glow plugs that would allow easier starting with ethanol. Finally, another approach to cold-starting is to blend ethanol with a more volatile fuel, such as gasoline. This is the approach used in the current generation of FFVs that use E85 in order to allow use of a conventional gasoline starting system (9).

Chang and Rudy noted that a California Air Resources Board (CARB) test of a 1987 Ford Crown Victoria FFV fueled with a mixture of $95 \%$ ethanol and 5\% gasoline (E95) had high coldstart emissions, with unburnt ethanol being the major component (11). This result suggests that blends with a higher content of gasoline should be used. However, one disadvantage of blending gasoline with ethanol is that ethanol/gasoline mixtures with low ethanol fractions will not remain mixed at low tempetatures unless the ethanol is anhydrous, or water-free. Thus, E85 must use anhydrous ethanol. This form of ethanol is currently used for blending in the United States, but an additional dehydration process is required to create anhydrous ethanol from hydrous ethanol. This 
dehydration process requires additional energy that can increase the global-warming impact of ethanol if fossil fuels are used (9).

Approximately 10 companies currently manufacture FFVs capable of using mixtures of gasoline and up to $85 \%$ ethanol. The technology is based on experience with neat-ethanol vehicles in Brazil and methanol FFVs in the United States. Most of the technology developed for methanol FFVs can be transferred directly to ethanol FFVs, but several adjustments must be made, including engine management, to account for the differences between methanol and ethanol. In addition, the corrosive characteristics of methanol and ethanol are not identical, and some components require material changes. To date, neat-ethanol vehicles have been produced in only limited quantities in the United States, and emissions testing on those vehicles is even more limited. Unfortunately, much of the emissions experience from neat-ethanol vehicles in Brazil is not directly transferrable to the U.S. situation because emission regulations in Brazil are much less strict (comparable to those of the early 1970 s in the United States) which resulted in development of different emissions control equipment.

Exhaust emissions of reactive $\mathrm{HC}$ and $\mathrm{CO}$ from $\mathrm{LPG}$ vehicles have been shown to be lower than those from gasoline vehicles, but $\mathrm{NO}_{\mathrm{x}}$ emissions have been about the same or higher $(3,5)$. Exhaust $\mathrm{HC}$ and $\mathrm{CO}$ emissions are lower because LPG allows more complete combustion due to its simple chemical composition, and the higher $\mathrm{NO}_{\mathrm{x}}$ emission rates are caused by a higher flame temperature in the combustion chamber. Cold-start exhaust emissions of $\mathrm{HC}, \mathrm{CO}$, and even $\mathrm{NO}_{\mathrm{x}}$ have been shown to be much less from LPG-fueled engines than from comparable gasoline-fueled engines (10).

The trade-off between $\mathrm{NO}_{\mathrm{x}}$ reductions and reductions of $\mathrm{CO}$ and $\mathrm{HC}$ also applies to $\mathrm{LPG}$ vehicles; thus, large reductions in $\mathrm{CO}$ and $\mathrm{NO}_{\mathrm{x}}$ emissions as compared with gasoline vehicles with comparable equipment are unlikely (12). Consequently, forthcoming EPA emissions standards for LPG-fueled light-duty vehicles will probably be numerically equivalent to those for gasoline-fueled vehicles. 
Modern LPG conversion vehicles with "intelligent" emission controls have demonstrated very low emission rates and dedicated vehicles that are developed specifically for LPG are expected to be able to meet even the ultra-low-emission-vehicle (ULEV) standards established for California (3). These dedicated LPG vehicles are likely to utilize direct injection of LPG into the fuel intake system instead of vaporization. The recently announced Ford medium-duty LPG trucks, with spark-ignition engines derived from the gasoline versions, meet all current federal and California emissions requirements (4).

\section{Compression-Ignition Engines}

Several diesel engine manufacturers, including Detroit Diesel, FEV of America, General Motors, John Deere, and Navistar, are now developing heavy-duty engines to operate on neat ethanol (13). Because neat ethanol has a lower cetane number than diesel fuel, it will not compression-ignite on its own. Cetane enhancers are available, but they are expensive and pose environmental concerns of their own. Other methods of using ethanol in compression-ignition engines are spark-ignition; dual-fuel systems that combine ethanol and diesel fuel; and exhaust gas recirculation (EGR) to provide adequate heat for combustion. Most manufacturers of diesel engines are adding spark plugs to allow existing engines to burn alternative fuels (14).

Alcohol-fueled heavy-duty engines developed by Detroit Diesel have demonstrated the ability to meet current and future EPA standards for $\mathrm{HC}, \mathrm{CO}$, and particulate matter, as shown in Table 4 (15). Current and near-future standards for $\mathrm{NO}_{\mathrm{x}}$ are also met, but 1998 standards for $\mathrm{NO}_{\mathrm{x}}$ are slightly exceeded with the E95 and M85 engines. Incomplete combustion of diesel fuel results in particulates that can reduce atmospheric visibility and carry carcinogens to human lungs, whereas engines designed to operate on ethanol are low in particulate generation. $\mathrm{CO}$ emissions from diesel-fuel engines are relatively low, but diesel engines running on alcohol at low loads could have increased $\mathrm{CO}$ emissions due to the poor ignition quality of alcohols relative to diesel fuel (10).

$\mathrm{NO}_{\mathrm{X}}$ emissions are expected to be reduced in compression-ignition engines using ethanol instead 
of diesel fuel (16). Also, the combustion of ethanol in heavy-duty engines should result in little or no sulfur dioxide $\left(\mathrm{SO}_{2}\right)$ emissions, because ethanol does not contain sulfur (unlike petroleum fuels).

As with ethanol, LPG will not ignite by compression alone due to its low cetane number; thus, ignition enhancement is necessary for compression-ignition engines to run on LPG. Factoryproduced LPG compression-ignition engines are not currently available in the United States for either light-duty or heavy-duty applications, but several manufacturers, including Cummins, are working on heavy-duty engines (3). Heavy-duty engines fueled with LPG are expected to have lower $\mathrm{HC}$ and $\mathrm{CO}$ emission rates as compared with gasoline and diesel fuel, and particulate emissions are expected to be much less than from diesel-fueled engines (14). Heavy-duty LPG engines could have low $\mathrm{NO}_{\mathbf{X}}$ emission rates if the engines use either lean combustion, internal exhaust gas recirculation, or stoichiometric combustion with a three-way catalytic converter (12).

\section{TOXIC EMISSIONS}

Ethanol itself is a central nervous system depressant and can be considered a toxic compound, but it is much less toxic to primates (humans) than methanol or gasoline. Potential sources of exposure to ethanol include fuel production, transportation, handling, combustion, and evaporation. Ethanol emissions from ethanol-fueled vehicles, including both evaporation and unburnt fuel, are not expected to generate concentrations that are toxic or carcinogenic (9). In fact, ethanol concentrations in air must exceed 1,000 parts per million (ppm) before symptoms such as headaches, eye irritation, drowsiness, irritation of the upper-respiratory tract, and the inability to

concentrate become apparent. By comparison, the odor threshold for ethanol is between 10 and $350 \mathrm{ppm}$; thus, it should be possible to avoid such symptoms (16).

Levels of benzene and polycyclic aromatic hydrocarbons (PAH) in the exhaust gases from ethanol engines are much lower than from gasoline engines. Pure ethanol does not contain benzene or any of the other named carcinogens, but fuel ethanol that contains gasoline (either as a denaturant 
or as a blending component) will contain small amounts of benzene. For example, E85 using gasoline with $1 \%$ benzene would contain $0.15 \%$ benzene (2).

Acetaldehyde emissions from neat-ethanol engines will be considerably higher than those from gasoline engines. In addition, the ethanol emitted from ethanol vehicles reacts in the atmosphere to create more acetaldehyde. Acetaldehyde reacts in the atmosphere to form peroxyacetyl nitrate (PAN), which plays a role in ozone formation and is an acute toxic compound. At high concentrations, PAN can produce eye irritation, blurred vision, and eye fatigue. However, ozone is likely to be a problem before PAN reaches irritant levels (9).

Brazilian studies have indicated that increased aldehyde emissions from ethanol-fueled vehicles lead to an increase in the formation rate of PAN (17). Other studies indicated that the high acetaldehyde concentrations in Brazilian urban areas, which are much higher than those measured elsewhere, are probably the result of the large-scale use of ethanol as a vehicle fuel in Brazil (18). However, it is difficult to extrapolate the Brazilian results to the United States because Brazilian vehicles do not use catalysts, and the application of three-way catalyst technology is a very effective way to reduce ethanol and aldehyde exhaust emissions to an acceptable level.

Acetaldehyde emissions from ethanol vehicles are much less carcinogenic than formaldehyde emissions from methanol vehicles. Ethanol-fueled vehicles are expected to generate formaldehyde emissions at a rate about equal to or slightly higher than gasoline vehicles, but much less than methanol vehicles with similar emission-control equipment. Aldehyde exposure can lead to headaches, nausea, and eye, nose, throat, and skin irritation. Ethanol engines are not expected to generate any 1,3-butadiene or polycyclic organic matter (POM), except to the extent that fuel ethanol contains gasoline. Similarly, fuel ethanol will not lead to any evaporative or refueling emissions of toxic compounds, except for those from any gasoline mixed with the ethanol (9).

Propane itself is considered nontoxic (10), and it is likely that LPG vehicles will produce lower emissions of the five air toxics (particulates, formaldehyde, acetaldehyde, benzene, and 1,3butadiene) as compared with gasoline (5). Benzene emissions from LPG vehicles are much less than from gasoline vehicles because LPG does not contain benzene, but formaldehyde and 
acetaldehyde emissions are about the same as from gasoline vehicles (12). Emissions of 1,3butadiene from LPG vehicles are expected to be less than from gasoline vehicles, and particulate emissions from LPG engines are expected to be much less than from diesel engines (5). Evaporative and refueling toxic emissions from LPG vehicles will be negligible.

\section{EVAPORATIVE AND REFUELING EMISSIONS}

Ethanol as E100 is significantly less volatile than gasoline (as shown by the vapor pressures in Table 1) and has a higher heat of vaporization; thus, ethanol use will result in fewer evaporative emissions than gasoline but more than diesel oil. This applies not only to evaporation from the

vehicle, but to the entire fuel cycle (16). However, FFVs will probably use E85, and the per-gallon evaporative losses from E85 or mixtures of E85 with gasoline that result in a lower ethanol content are expected to be comparable to those from gasoline (2). These evaporative emissions have a higher fraction of gasoline nonmethane hydrocarbons (NMHC) than exists in the fuel itself. Also, ethanol's lower energy content compared with gasoline could lead to larger fuel tanks or an increase in refueling frequency (10). Thus, if the grams-per-gallon evaporative and refueling emissions from E85 are the same as from gasoline, but the amount of fuel required per mile increases by $21 \%$, then the grams-per-mile emissions could increase by $21 \%$ as well.

Dedicated LPG vehicles will not have evaporative losses (hot soak, diurnal, and running), but they will have small, measurable refueling losses (12). Evaporative emissions will be negligible because the fuel system must be closed and leak-proof in order to handle the LPG that is stored and distributed under pressure (about $200 \mathrm{psi}$ ). Small refueling losses will result from connecting and disconnecting the fuel-line fittings at the vehicle interface. Refueling losses can be reduced even further with a new type of filler valve that has been developed to prevent overfilling and LPG loss (3). This should enable dedicated LPG vehicles to meet any future evaporative emission standards. Dual-fuel LPG vehicles will have both LPG and gasoline fuel systems; thus, the evaporative 
emissions from these vehicles would be almost as high as from gasoline vehicles, and the refueling emissions would be only slightly less (assuming less frequent gasoline refueling).

\section{OZONE FORMATION}

The ozone-forming potential of one gram of organic emissions depends on the detailed composition or speciation of the emissions and on the composition of the atmosphere. The Carter reactivities of some of the exhaust and evaporative emission components from alternative fuels are shown in Table 5. The reactivity of a gas is a measure of how much ozone will be formed by emission of one gram of that gas. The term nonmethane organic gas (NMOG) is usually used when discussing ozone formation. NMOG includes all NMHC as well as alcohols and aldehydes. Methane is excluded because its ozone reactivity is very small as compared with the other gases, as indicated in Table 5. In general, the reactivities of emission components that are likely to be increased from alternative-fueled vehicles are less than the reactivity of gasoline NMHC, except for the aldehydes, which are highly reactive.

Chang and Rudy (11) have shown that the ozone-forming potential of emissions from alternative fuels also depends on the NMOG to $\mathrm{NO}_{\mathrm{X}}$ ratio in the atmosphere, as shown in Figure 1. At low NMOG/NO ${ }_{x}$ ratios, the ozone-forming potential (per carbon) of emissions from E95 and LPG vehicles is less than that of gasoline vehicles, but the potentials are equivalent at high ratios. Thus, Table 5 shows reactivity values for two different situations. The maximum incremental reactivity (MIR) is appropriate when the reaction is limited by organic content (NMOG), and the maximum ozone reactivity (MOR) is appropriate when the reaction is limited by $\mathrm{NO}_{\mathrm{x}}$ content.

CARB has proposed a set of reactivity adjustment factors (RAFs) for transitional lowemission vehicles (TLEVs) running on alternative fuels (7). These RAF values, listed in Table 6, were derived from photochemical modeling of speciated exhaust emission profiles from a series of emission tests. The RAF values represent the relative amount of ozone formed by a given mass of exhaust NMOG emissions, as compared with industry average gasoline. Thus, by definition, the 
reactivity adjustment factor of (industry average) gasoline is 1.00. All of the alternative fuels listed in Table 6 are expected to be less reactive than gasoline, with natural gas being the least reactive followed by methanol, LPG, and ethanol. RAF values from both the MIR and MOR methods are listed because they bracket the range of conditions under which $\mathrm{HC}$ reactivity can be appropriately defined. CARB recommends using the MIR values in California because they reflect the conditions where $\mathrm{HC}$ control has the greatest impact on ozone formation. It should be noted that only the M85 values have been approved so far, and that the other RAF values could be adjusted by as much as $10 \%$. The ethanol values are estimated on the basis of two M85 FFVs running on E85 fuel, and the RAF values for LPG are estimated on the basis of two gasoline vehicles that were converted to run on LPG (results are shown in Table 3).

In the future CARB will calculate RAF values using reformulated gasoline (RFG) as the reference fuel. Since RFG is less reactive than industry average gasoline, all of the RAF values will increase, but the relative ranking of the alternative fuels will stay the same.

A portion of the ethanol that enters an engine as fuel exits unburned and becomes the major component of the exhaust NMOG emissions. Ethanol is more reactive than primary components of other alternative fuels, but still less reactive than gasoline. Aldehydes are formed as products of incomplete combustion in engines, and fuel ethanol leads to acetaldehyde as the primary aldehyde in the exhaust. Other aldehydes, such as formaldehyde, are present, but in much smaller quantities. Aldehydes are among the more reactive contributors to ozone formation, but the contribution of aldehyde exhaust emissions to atmospheric aldehyde concentrations is a matter of current scientific debate. Aldehydes in the atmosphere tend to result from reactions of other carbon-containing compounds, rather than directly from vehicle exhaust. However, aldehyde concentrations in parking garages and personal garages tend to be the result of vehicle exhaust (2).

Unburned propane, the major component of LPG, accounts for a large fraction of the exhaust NMOG emissions from LPG-fueled vehicles. Fortunately, propane is less reactive than gasoline and most other alternative fuel components except for methane, which is the major component of natural gas (2). Exhaust emissions from LPG vehicles contain relatively high levels 
of reactive olefin compounds (5), but reactive aldehyde emissions from LPG vehicles are low. Taken together, these factors combine to give a low RAF for exhaust emissions from LPG vehicles.

The reactivity adjustment factors developed by CARB apply to exhaust emissions only. For evaporative emissions, the individual emission components must be multiplied by the relative reactivity of each component (from Table 5) as compared with gasoline evaporative emissions. The reactivities of the alternative-fuel components are much less than the reactivity of gasoline; thus, an equivalent mass of evaporative emissions from an alternative fuel will be much less than that from gasoline. Chang, et al. considered the relative ozone-forming potential (per mile) of exhaust plus evaporative emissions from alternative-fuel vehicles relative to gasoline-fuel vehicles, assuming all vehicles meet the same exhaust emission standards and have comparable control technologies (5). They concluded that neat-ethanol vehicles will have a relative ozone-forming potential (per mile) about $80 \%$ (plus or minus $20 \%$ ) as high as for gasoline vehicles, with the major benefit associated with a reduction in evaporative emissions. They estimated the same relative potential (80\%) for reformulated gasoline and diesel vehicles, and a value of $65 \%$ (plus or minus $20 \%$ ) for LPG vehicles. Values for M85 and compressed natural gas (CNG) were estimated as $70 \%$ (plus or minus $20 \%$ ) and $40 \%$ (plus or minus $20 \%$ ), respectively.

\section{GLOBAL WARMING}

The production and combustion of ethanol and LPG generate $\mathrm{CO}_{2}$, and other "greenhouse gases" that result from incomplete combustion and could contribute to global warming. If ethanol is made from biomass, the $\mathrm{CO}_{2}$ emissions from combustion and fermentation are reabsorbed by the growing biomass. However, ethanol requires processing energy to plant, fertilize, harvest, and ferment the crop, and for distillation and transportation. With current production methods, much of this energy is obtained from fossil fuels, and the total amount of processing energy can be close to the energy content of the ethanol produced. Attributing some of the $\mathrm{CO}_{2}$ emissions from the 
processing of ethanol to its coproducts reduces the burden on ethanol, but there is controversy regarding exactly how to distribute the emissions (19).

Other factors that determine the global warming impact of ethanol include crop yield, nitrous oxide releases from fertilizer use, processing efficiency, and the type of energy used in processing. The emerging consensus is that ethanol's contribution to global warming would be about the same as that of gasoline. Ethanol from such cellulosic biomass as municipal waste, grass, or wood could lead to a net global warming reduction if the feedstock does not require too much energy input for collection and conversion (2).

DeLuchi provides the most comprehensive estimates of total fuel-cycle emissions of greenhouse gases from motor vehicles (20). He compares the emissions of all greenhouse gases from ethanol and LPG (and other alternative fuels) with the emissions from gasoline and diesel fuel, on the basis of grams of $\mathrm{CO}_{2}$-equivalent emissions per mile. The results, summarized in Table 7 , depend strongly on the assumptions used in the analysis. For the base case (his best estimate), DeLuchi estimates that ethanol from wood (cellulosic biomass) reduces the per-mile emissions of greenhouse gases by about $70 \%$, as compared with gasoline and diesel fuel. This reduction comes from reduced tailpipe emissions (since the carbon originally comes from the atmosphere) and reduced emissions from the wood-to-ethanol production plants that use a part of the wood as a process fuel. These plants would probably produce more electricity than they need and could sell the excess, resulting in a credit for the ethanol.

The results for ethanol from corn are not as promising. Using coal as the process fuel, DeLuchi estimates that ethanol from corn would cause an increase in greenhouse-gas emissions by about $20 \%$ for a light-duty vehicle (as compared with gasoline) and by almost $50 \%$ for a heavyduty vehicle (as compared with diesel fuel) (20). The two sources in the corn-to-ethanol cycle that generate large amounts of emissions are combustion of coal at the ethanol production plant and the use of fertilizers in corn farming (since nitrogen-containing fertilizers can denitrify to produce nitrous oxide $\left(\mathrm{N}_{2} \mathrm{O}\right)$ which is a greenhouse gas). As an indication of the sensitivity of the results to the assumptions, the use of corn stover (crop residue) as a process fuel instead of coal leads to a 
reduction in greenhouse-gas emissions by about $17 \%$ for light-duty vehicles using ethanol from corn, as compared with gasoline. Other changes in assumptions can provide equally dramatic shifts in the results.

Greenhouse-gas emissions from the use of LPG depend on whether the LPG comes from petroleum refineries or from natural-gas plants. Using the current United States mix of about $60 \%$ LPG from natural gas and 40\% LPG from petroleum, DeLuchi estimates that use of LPG reduces greenhouse-gas emissions by about $20 \%$ for a light-duty vehicle (as compared with gasoline) and by only about $2 \%$ for a heavy-duty vehicle (as compared with diesel fuel) (20). The reduction for a light-duty vehicle comes from the lower carbon content of LPG, lower CO emissions, and higher efficiency as compared with gasoline vehicles. LPG also has lower upstream emissions of greenhouse gases because it takes less energy to process LPG as compared with other fuels (2I).

\section{AGRICULTURAL EMISSIONS}

Corn farming uses large amounts of nitrogen, phosphorous, and potassium fertilizers, and these fertilizers contain various amounts of embodied energy used in their production. Increased production of corn to provide ethanol feedstock might result in increased use of nitrogen fertilizers that can lead to emissions of both $\mathrm{NO}_{\mathrm{X}}$, which contribute to ozone formation, and $\mathrm{N}_{2} \mathrm{O}$, an important greenhouse gas. Deluchi estimates both the emissions of $\mathrm{NO}_{\mathrm{X}}$ from the nitrification of fertilizer and the emissions of $\mathrm{N}_{2} \mathrm{O}$ from the denitrification of fertilizer (20). The net amount of $\mathrm{NO}_{\mathbf{x}}$ and $\mathrm{N}_{2} \mathrm{O}$ released depends on the amount and type of fertilizer, soil and weather conditions, agricultural practices, and other factors. For corn farming, DeLuchi estimates that about $2.6 \%$ of the nitrogen in fertilizer ends up as nitrogen in $\mathrm{N}_{2} \mathrm{O}$ in the air and about $0.8 \%$ ends up as nitrogen in NO $\left(\mathrm{NO}_{\mathrm{x}}\right)$. For cellulosic biomass crops which use fertilizer, he estimates that about $0.6 \%$ of the nitrogen in fertilizer ends up as nitrogen in $\mathrm{N}_{2} \mathrm{O}$ and about $0.8 \%$ ends up as nitrogen in NO. However, DeLuchi cautions that these estimates are highly uncertain. 


\section{SUMMARY}

Neat-ethanol-fueled vehicles (E85 and higher) are expected to emit more ethanol and acetaldehyde in the exhaust than gasoline-fueled vehicles, but total exhaust HC and NMOG emissions should decrease. $\mathrm{NO}_{\mathbf{X}}$ formation could be lower with use of neat ethanol than with gasoline, because the combustion temperature will be lower, but tailpipe emission rates will probably be equivalent to those from gasoline vehicles with comparable control technology. Similarly, there is no reason to expect lower $\mathrm{CO}$ emission rates from neat-ethanol vehicles. The vapor pressure of pure ethanol is much lower than gasoline, which would result in lower evaporative emissions for neat-ethanol vehicles (E85 and higher). However, this can also cause cold-starting problems and result in higher cold-start exhaust emissions ( $\mathrm{HC}$ and $\mathrm{CO}$ ).

LPG-fueled vehicles using current aftermarket conversion technologies have shown equivalent or better emission performance as compared with gasoline vehicles, and dedicated OEM vehicles should offer substantial emission reductions. Exhaust emissions of unburned propane will be higher than from gasoline vehicles, but total HC and NMOG emissions should decrease. $\mathrm{CO}$ and $\mathrm{NO}_{\mathrm{X}}$ emissions from light-duty LPG vehicles are not expected to be significantly less than from gasoline vehicles with comparable control equipment. However, significant $\mathrm{NO}_{\mathbf{x}}$ and particulate emissions reductions are expected from heavy-duty LPG engines, as compared with diesel engines, along with minor HC and CO reductions. Dedicated LPG vehicles will not have evaporative losses, but they will have small refueling losses.

Neat-ethanol-fueled vehicles are expected to reduce total air toxic and particulate emissions. Benzene emissions would be virtually eliminated except for the contribution from any gasoline mixed with the ethanol. Similarly, ethanol itself is not expected to produce any significant $1,3-$ butadiene emissions. Formaldehyde emissions from neat-ethanol engines are expected to be about the same as or slightly higher than emissions from gasoline engines. Acetaldehyde emissions from neat-ethanol vehicles can be much higher than from gasoline engines, but this is not expected to be a major concern because acetaldehyde has a much lower carcinogenic potential than formaldehyde. 
LPG-fueled vehicles are also expected to reduce total air toxic and particulate emissions. Emissions of 1,3-butadiene from LPG vehicles is expected to be less than from gasoline vehicles, and benzene emissions should be much less. Formaldehyde and acetaldehyde emissions from LPG engines are expected to be about the same as or slightly less than from gasoline engines.

Limited ozone modelling of speciated emissions from neat ethanol-fueled vehicles suggest that the ozone-forming potential of neat-ethanol is less than that of gasoline and diesel fuel; about the same as that of reformulated gasoline; and higher than that of other alternative fuels. The ozone-forming potential of emissions from LPG vehicles should be less than from neat-ethanol vehicles (thus, much less than from gasoline vehicles) but greater than from methanol and natural gas vehicles.

Some of the limitations of pure ethanol, such as cold-start problems and the requirement of dedicated vehicles, can be overcome by blending ethanol with gasoline to form E85, which can be used in dedicated or FFVs. However, using blends tends to diminish the inherent benefits of using ethanol in the first place, such as low volatility and no benzene. FFVs running on mixtures of E85 and gasoline are likely to have higher evaporative emissions than gasoline vehicles. Similarly, dualfuel vehicles with both gasoline- and LPG-fuel systems have been developed, but these vehicles cannot be optimized for both fuels simultaneously, and evaporative emissions tend to be almost as high as from gasoline vehicles.

There is no net increase in $\mathrm{CO}_{2}$ from the combustion of ethanol. However, $\mathrm{CO}_{2}$ and other greenhouse gases are created during the production and transportation of ethanol. Furthermore, the combustion of ethanol creates other exhaust gases besides $\mathrm{CO}_{2}$ that may contribute to global warming. There is some controversy regarding the net impact of ethanol fuel on global warming, but it is possible that the impact of producing ethanol from corn could be somewhat worse than producing gasoline. Ethanol produced from cellulosic biomass (i.e., wood, grass, or waste) is expected to have less of a global-warming impact, especially if efficient production processes can be developed. The production and combustion of LPG in a light-duty vehicle generates fewer 
greenhouse-gas emissions than a gasoline vehicle, but the greenhouse-gas emissions from a heavyduty LPG vehicle are about the same as from a diesel vehicle.

Increased production of ethanol from corn using nitrogen fertilizers could lead to increased emissions of both $\mathrm{NO}_{\mathbf{x}}$, which contributes to ozone formation, and $\mathrm{N}_{2} \mathrm{O}$, an important greenhouse gas.

\section{ACKNOWLEDGEMENT}

Work sponsored by the United States Department of Energy, Deputy Under Secretary for Policy, Planning and Analysis, Office of Environmental Analysis, under contract W-31-109-Eng-38.

\section{REFERENCES}

1. M.J. Murphy. Properties of Alternative Fuels. Report No. FTA-OH-06-0060-92-5. Prepared for the U.S. Department of Transportation, Federal Transit Administration by Battelle, Columbus, Ohio, August 1992.

2. D.E. Gushee. Alternative Fuels for Automobiles: Are They Cleaner than Gasoline? Report No. 92-235 S. Congressional Research Service, Library of Congress, Washington, D.C., February 27, 1992.

3. R. F. Webb Corporation. Investigation Regarding Federal Policy Actions for Encouraging Use of Liquified Petroleum Gas as a Motor Vehicle Fuel - Final Report. Congressional Research Service, Library of Congress, Washington, D.C., April 1992.

4. New Fuels Report . Various Issues, 1992. 
5. T.Y. Chang, R. H. Hammerle, S. M. Japar, and I. T. Salmeen. Alternative Transportation Fuels and Air Quality. Environmental Science \& Technology, Vol. 25, No. 7, 1991, pp. 1190-1197.

6. G.J. Barnes, General Motors Corporation. Presentation at the Conference on New Fuels and Vehicles for Cleaner Air, Phoenix, Arizona, February 25-26, 1992.

7. California Air Resources Board. Proposed Reactivity Adjustment Factors for Transitional Low-Emission Vehicles. Technical Support Document. California Air Resources Board, Sacramento, California, September 27, 1991.

8. C.B. Prakash. Emission Performance of Four Identical Passenger Cars Running on Gasoline, M85, CNG and LPG. Air \& Waste Management Association Paper No. 91-106.9. Presented at the 84th Annual Meeting, Vancouver, British Columbia, June 16-21, 1991.

9. Environmental Protection Agency, Office of Mobile Sources. Analysis of the Economic and Environmental Effects of Ethanol as an Automotive Fuel. Special Report. EPA, Ann Arbor, Michigan, April 1990.

10. M. Heath. Alternative Transportation Fuels: Natural Gas, Propane, Methanol \& Ethanol compared with Gasoline \& Diesel. Study No. 37. Canadian Energy Research Institute, Calgary, Alberta, February 1991.

11. T.Y. Chang, and S. J. Rudy. Ozone-Forming Potential of Organic Emissions from AlternativeFueled Vehicles. Air \& Waste Management Association Paper No. 90-96.3. Presented at the 83rd Annual Meeting, Pittsburgh, Pennsylvania, June 24-29, 1990. 
12. R.F. Klausmeier and J. Draves. Assessment of Environmental Issues Related to the Use of Alternative Transportation Fuels - Analysis of Recent Data. Air \& Waste Management Association Paper No. 91-106.3. Presented at the 84th Annual Meeting, Vancouver, British Columbia, June 16-21, 1991.

13. Information Resources, Inc. Accelerating the Market Penetration of Fuel Ethanol. Congressional Research Service, Library of Congress, Washington, D.C., April 24, 1992.

14. R.F. Klausmeier. Assessment of Environmental, Health, and Safety Issues Related to the Use of Alternative Transportation Fuels. Report No. GRI-89/0249, Gas Research Institute, Chicago, lllinois, October 1989.

15. Detroit Diesel Corporation. Alcohol Engine Program. Information Update. Vol. 5, No. 2, December 1992, p. 9.

16. Swedish Motor Fuel Technology Co. Alcohols and Alcohol Blends as Motor Fuels: State-ofthe-Art Report. International Energy Agency, Swedish National Board for Technical Development, Stockholm, Sweden, October 1986.

17. R.L. Tanner, A. H. Miguel, J. B. de Andrade, J. S. Gaffney, and G. E. Streit. Atmospheric Chemistry of Aldehydes: Enhanced Peroxyacetyl Nitrate Formation from Ethanol-Fueled Vehicular Emissions. Environmental Science \& Technology, Vol. 22, No. 9, 1988, pp. 10261034.

18. D. Grosjean, A. H. Miguel, and T. M. Tavares. Urban Air Pollution in Brazil: Acetaldehyde and Other Carbonyls. Atmospheric Environment, Vol. 24B, No. 1, 1990, pp. 101-106. 
19. G. Marland and A. F. Turhollow. $\mathrm{CO}_{2}$ Emissions from the Production and Combustion of Fuel Ethanol from Corn. Oak Ridge National Laboratory, Oak Ridge, Tennessee February 1991. Forthcoming in Energy - The International Journal.

20. M.A. DeLuchi. Emissions of Greenhouse Gases from the Use of Transportation Fuels and Electricity. Technical Memo No. ANL/ESD/TM-22. Argonne National Laboratory, Argonne, Illinois, November 1991.

21. F. Stodolsky and D.J. Santini. The Efficient Use of Natural Gas in Transportation. Presented at the Annual Meeting of the American Chemical Society, San Francisco, California, April 5-10, 1992. 
TABLE 1 Properties of Gasoline, Diesel, Ethanol and Propane

\begin{tabular}{|c|c|c|c|c|}
\hline \multicolumn{5}{|l|}{$\begin{array}{l}\text { Properties } \\
\text { Chemical Properties }\end{array}$} \\
\hline $\begin{array}{l}\text { Formula } \\
\text { Molecular weight }\end{array}$ & $\begin{array}{r}\mathrm{C}_{4}-\mathrm{C}_{12} \\
100-105\end{array}$ & $\begin{array}{r}\mathrm{C}_{14}-\mathrm{C}_{19} \\
\mathrm{~N} / \mathrm{A}^{\mathrm{a}}\end{array}$ & $\mathrm{C}_{2} \mathrm{H}_{5} \mathrm{OH}$ & $\begin{array}{r}\mathrm{C}_{3} \mathrm{H}_{8} \\
44\end{array}$ \\
\hline \% carbon (by weight) & $85-88$ & 87 & 52 & 82 \\
\hline$\%$ hydrogen (by weight) & $12-15$ & 13 & 13 & 18 \\
\hline$\%$ oxygen (by weight) & indefinite & 0 & 35 & \\
\hline $\mathrm{C} / \mathrm{H}$ ratio (by weight) & $5.6-7.4$ & 7.0 & 4.0 & 4.6 \\
\hline Stoichiometric air-to-fuel ratio & $14.2-15.1$ & $14.5-15.1$ & 9.0 & 15.7 \\
\hline \multicolumn{5}{|l|}{ Physical Properties } \\
\hline Specific gravity & $0.70-0.78$ & $0.79-0.88$ & 0.79 & 0.51 \\
\hline Liquid density (lb/gal) & $5.8-6.5$ & $7.1-7.5$ & 6.6 & 4.2 \\
\hline Vapor pressure at $100^{\circ} \mathrm{F}(\mathrm{psi})$ & $7-15(\mathrm{RVP})^{\mathrm{b}}$ & negligible & 2.5 & 196 \\
\hline Boiling point $\left({ }^{\circ} \mathrm{F}\right)$ & $80-440$ & $360-600$ & 173 & -44 \\
\hline Solubility in water (ppm) & 240 & none & infinite & negligible \\
\hline \multicolumn{5}{|l|}{ Thermal Properties } \\
\hline Lower heating value (Btu/gal) & 118,000 & 131,000 & 76,000 & 85,000 \\
\hline Higher heating value (Btu/gal) & 122,000 & 139,000 & 84,400 & 92,000 \\
\hline Heat of vaporization (Btu/gal) & 900 & $700-1400$ & 2,700 & 770 \\
\hline Research octane rating & 98 & N/A & $106-108$ & 107 \\
\hline Motor octane rating & $83-90$ & N/A & 92 & 94 \\
\hline Flammability limits (\% vol. in air) & $1.4-7.6$ & $0.6-5.5$ & 3.3-19 & $2.1-9.5$ \\
\hline Specific heat (Btu/lb-oF) & 0.48 & N/A & 0.60 & 0.63 \\
\hline Autoignition temperature (OF) & $430-500$ & $400-500$ & 685 & $920-1,120$ \\
\hline Flash point (OF) & -50 & $110-190$ & 55 & -155 \\
\hline
\end{tabular}

a N/A = not available.

b RVP = Reid vapor pressure.

Source: Reference 1. 
TABLE 2 Summary of Emissions from Ethanol and LPG Vehicles

\begin{tabular}{llllll}
\hline Issue & Gasoline & RFG & Diesel & Ethanol & LPG \\
\hline Emission Rate (Compared to Gasoline) & & & & \\
NMOGc & Base & Lower & Lower & Lower & Lower \\
CO & Base & Lower & Lower & Equal & Lower \\
NOx & Base & Equal & Higher & Equal & Higher \\
Evaporative & Base & Lower & Lower & Lower & Lower \\
Ozone-forming Potential & 1.00 & $0.8 \pm 0.2$ & $0.8 \pm 0.2$ & $0.8 \pm 0.2$ & $0.65 \pm 0.2$ \\
Toxic Emissions & & & & & \\
Particulate & Low & Low & High & Low & Low \\
1,3-Butadiene & Medium & Medium & Unknown & Low & Low \\
Benzene & High & Medium & Low-Med. & Low & Low \\
Formaldehyde & Medium & Medium & Medium & Medium & Low \\
Acetaldehyde & Low & Low & Low & High & Low \\
Global Warming & & & & & \\
Grams of CO2/Btu & 0.094 & 0.094 & 0.096 & 0.083 & 0.081 \\
Fuel economy (mpg) & 34 & 34 & $39-48$ & 28 & 31 \\
Energy use (Btu/mile) & 3,350 & 3,350 & $3,260-2,610$ & 2,920 & 2,830 \\
Grams of CO2/mile & 315 & 315 & $313-252$ & 243 & 229 \\
\hline
\end{tabular}

a Current industry average gasoline.

b Reformulated gasoline.

c $\mathrm{NMOG}=$ Nonmethane organic gas.

d Values are for net $\mathrm{CO}_{2}$ emissions from production, transportation, and combustion of the fuel. Ethanol values exclude combustion emissions and assume coproduct credits.

Source: Adopted from Reference 5. 
TABLE 3 Emission Rates for Ethanol and LPG Vehicles as Compared with Similar Vehicles

\begin{tabular}{|c|c|c|c|c|c|c|c|c|c|}
\hline \multirow[b]{2}{*}{ Vehicle } & \multirow[b]{2}{*}{ Fuel } & \multicolumn{7}{|c|}{ FTP Emission Rate (grams per mile) } & \multirow[b]{2}{*}{ Source } \\
\hline & & Total HC & $\mathrm{NMOG}^{\mathbf{a}}$ & $\begin{array}{l}\text { Unburnt } \\
\text { Fuelb }\end{array}$ & $\begin{array}{l}\text { Form- } \\
\text { aldehyde }\end{array}$ & $\begin{array}{l}\text { Acet- } \\
\text { aldehyde }\end{array}$ & $\mathrm{CO}$ & $\mathrm{NOx}$ & \\
\hline 92 Chevy Lumina VFV & $\mathrm{E} 85$ & & 0.16 & & 0.005 & 0.021 & 0.50 & 0.19 & Ref. 6 \\
\hline 92 Chevy Lumina VFV & M85 & & 0.18 & & 0.018 & & 1.50 & 0.21 & Ref. 6 \\
\hline 91 Chevy Lumina VFV & $\mathrm{E} 85^{\mathrm{c}}$ & 0.32 & 0.26 & 0.19 & 0.005 & 0.021 & 1.70 & 0.26 & Ref. 7 \\
\hline 91 Chevy Lumina VFV & M85 & 0.29 & 0.27 & 0.21 & 0.015 & 0.001 & 2.46 & 0.24 & Ref. 7 \\
\hline 91 VW Jetta FFV & $\mathrm{E} 85^{\mathrm{c}}$ & 0.36 & 0.30 & 0.22 & 0.005 & 0.022 & 4.04 & 0.06 & Ref. 7 \\
\hline 91 VW Jetta FFV & M85 & 0.29 & 0.28 & 0.23 & 0.018 & 0.001 & 2.59 & 0.06 & Ref. 7 \\
\hline 89 Olds Delta $88^{d}$ & LPG & 0.16 & 0.11 & 0.07 & 0.001 & 0.001 & 2.68 & 0.11 & Ref. 7 \\
\hline 89 Olds Delta $88^{d}$ & Gasoline & 0.12 & 0.10 & & 0.001 & 0.001 & 2.21 & 0.45 & Ref. 7 \\
\hline 89 Pontiac 6000 LE & LPG & 0.14 & 0.10 & 0.07 & 0.004 & 0.001 & 0.72 & 0.29 & Ref. 7 \\
\hline 90 Ford Taurus ${ }^{\mathrm{d}}$ & LPG & & 0.16 & & 0.006 & 0.001 & 1.71 & 0.86 & Ref. 8 \\
\hline 90 Ford Taurus ${ }^{d}$ & Gasoline & & 0.18 & & 0.005 & 0.002 & 1.56 & 0.53 & Ref. 8 \\
\hline
\end{tabular}

a $\mathrm{NMOG}=$ nonmethane organic gas.

b Ethanol for E85, methanol for M85, propane for LPG.

c Vehicle designed to run on M85.

d Dual-fuel vehicles. 
TABLE 4 Emission Rates for Heavy-Duty Alcohol Engines as Compared with EPA Standards

\begin{tabular}{|c|c|c|c|c|c|c|}
\hline \multirow[b]{2}{*}{ Vehicle } & \multirow[b]{2}{*}{ Fuel } & \multicolumn{4}{|c|}{ Emission Rate (grams/bhp-hour) } & \multirow[b]{2}{*}{$\begin{array}{l}\text { Particulate } \\
\text { Matter }\end{array}$} \\
\hline & & Total HC & OMHCE & $\mathrm{CO}$ & $\mathrm{NO}_{\mathbf{X}}$ & \\
\hline 92 DDC 6V-92TA ${ }^{b}$ & E95 & & 0.73 & 1.71 & 4.15 & 0.04 \\
\hline 92 DDC 6V-92TA & M100 & & 0.10 & 2.05 & 1.70 & 0.03 \\
\hline 92 DDC 6V-92TA & M85 & & 0.23 & 1.60 & 4.05 & 0.03 \\
\hline 91 Heavy-Duty Standard & & 1.3 & & 15.5 & 5.0 & 0.25 \\
\hline 93 Urban Bus Standard & & 1.3 & & 15.5 & 5.0 & 0.10 \\
\hline 94 Heavy-Duty Standard & & 1.3 & & 15.5 & 5.0 & 0.10 \\
\hline 94 Urban Bus Standard & & 1.3 & & 15.5 & 5.0 & $0.05^{c}$ \\
\hline 98 Heavy-Duty Standard & & 1.3 & & 15.5 & 4.0 & 0.10 \\
\hline 98 Urban Bus Standard & & 1.3 & & 15.5 & 4.0 & $0.05^{\mathrm{c}}$ \\
\hline
\end{tabular}

a $\mathrm{OMHCE}=$ organic material hydrocarbon equivalent.

b This Detroit Diesel Corporation urban bus engine is turbocharged and aftercooled.

Emission rates shown are with a catalyst.

c EPA can relax particulate matter standard for urban buses to 0.07 if 0.05 is not achievable.

Source: Reference 15. 
TABLE 5 Reactivities for Emissions from Alternative Fuels

\begin{tabular}{|c|c|c|}
\hline \multirow[b]{2}{*}{ Component } & \multicolumn{2}{|c|}{$\begin{array}{c}\text { Reactivity } \\
\text { (grams of ozone per gram of } \mathrm{NMOG}^{\mathrm{a}} \text { ) }\end{array}$} \\
\hline & MIR $^{b}$ & $\mathrm{MOR}^{\mathrm{c}}$ \\
\hline Gasoline NMHCa,d & 3.44 & 1.30 \\
\hline Methanol & 0.56 & 0.28 \\
\hline Ethanol & 1.33 & 0.72 \\
\hline Formaldehyde & 7.14 & 2.08 \\
\hline Acetaldehyde & 5.51 & 2.17 \\
\hline Methane & 0.01 & 0.01 \\
\hline Ethane & 0.26 & 0.18 \\
\hline Propane & 0.48 & 0.31 \\
\hline Butane & 1.02 & 0.66 \\
\hline Pentane & 1.03 & 0.68 \\
\hline
\end{tabular}

a NMOG = nonmethane organic gas; NMHC = nonmethane hydrocarbons.

b Maximum incremental reactivity (MIR) is appropriate when the reaction is limited by organic content. CARB recommends the use of MIR values in California.

$\mathrm{c}^{\mathrm{c}}$ Maximum ozone reactivity (MOR) is appropriate when the reaction is limited by $\mathrm{NO}_{\mathrm{x}}$ content. d Gasoline contains components with MIRs ranging from less than 1 to about 10 and MORs up to about 3. The numbers cited are from exhausts, not from evaporation.

Sources: References 2 and 7. 
TABLE 6 CARB Reactivity Adjustment Factors for Light-Duty TLEVs

\begin{tabular}{lcccc}
\hline & \multicolumn{4}{c}{ Reactivity } \\
\cline { 2 - 5 } Method & M85 & E85 & LPG & CNG \\
\hline MIR $^{\mathrm{a}}$ & $0.36^{\mathrm{b}}$ & 0.63 & 0.50 & 0.18 \\
MORc & 0.38 & 0.77 & 0.59 & 0.24 \\
\hline
\end{tabular}

a Maximum incremental reactivity (MIR) is appropriate when the reaction is limited by organic content. CARB recommends the use of MIR values in California.

$\mathrm{b}$ CARB later adapted a generic reactivity adjustment factor of 0.41 for M85.

c. Maximum ozone reactivity (MOR) is appropriate when the reaction is limited by $\mathrm{NO}_{\mathrm{x}}$ content. Source: Reference 7. 
TABLE 7 Total Fuel Cycle Greenhouse-Gas Emissions from Ethanol and LPG Vehicles as Compared with Gasoline and Diesel Fuel

\begin{tabular}{|c|c|c|c|}
\hline & \multicolumn{3}{|c|}{$\begin{array}{c}\text { Change in } \mathrm{CO}_{2} \text {-Equivalent Greenhouse Gas } \\
\text { Emissions (grams per mile) }\end{array}$} \\
\hline & Best Case & Best Estimate & Worst Case \\
\hline \multicolumn{4}{|l|}{$\begin{array}{l}\text { Light-Duty Vehicles Compared } \\
\text { to Reformulated Gasoline }\end{array}$} \\
\hline Ethanol from wood (cellulose) & $-85 \%$ & $-73 \%$ & $-25 \%$ \\
\hline Ethanol from corn & $-62 \%$ & $+20 \%$ & $+50 \%$ \\
\hline LPG from natural gas and oil & $-31 \%$ & $-23 \%$ & $-8 \%$ \\
\hline Diesel fuel & $-22 \%$ & $-14 \%$ & $-8 \%$ \\
\hline \multicolumn{4}{|l|}{$\begin{array}{l}\text { Heavy-Duty Vehicles Compared } \\
\text { to Reformulated Diesel Fuel }\end{array}$} \\
\hline Ethanol from wood (cellulose) & $\mathrm{N} / \mathrm{A}^{\mathrm{a}}$ & $-71 \%$ & N/A \\
\hline Ethanol from com & $+41 \%$ & $+49 \%$ & N/A \\
\hline LPG from natural gas and oil & $-10 \%$ & $-2 \%$ & $+19 \%$ \\
\hline Reformulated gasoline & N/A & $+23 \%$ & $+31 \%$ \\
\hline
\end{tabular}

a N/A $=$ not available.

Source: Reference 20. 


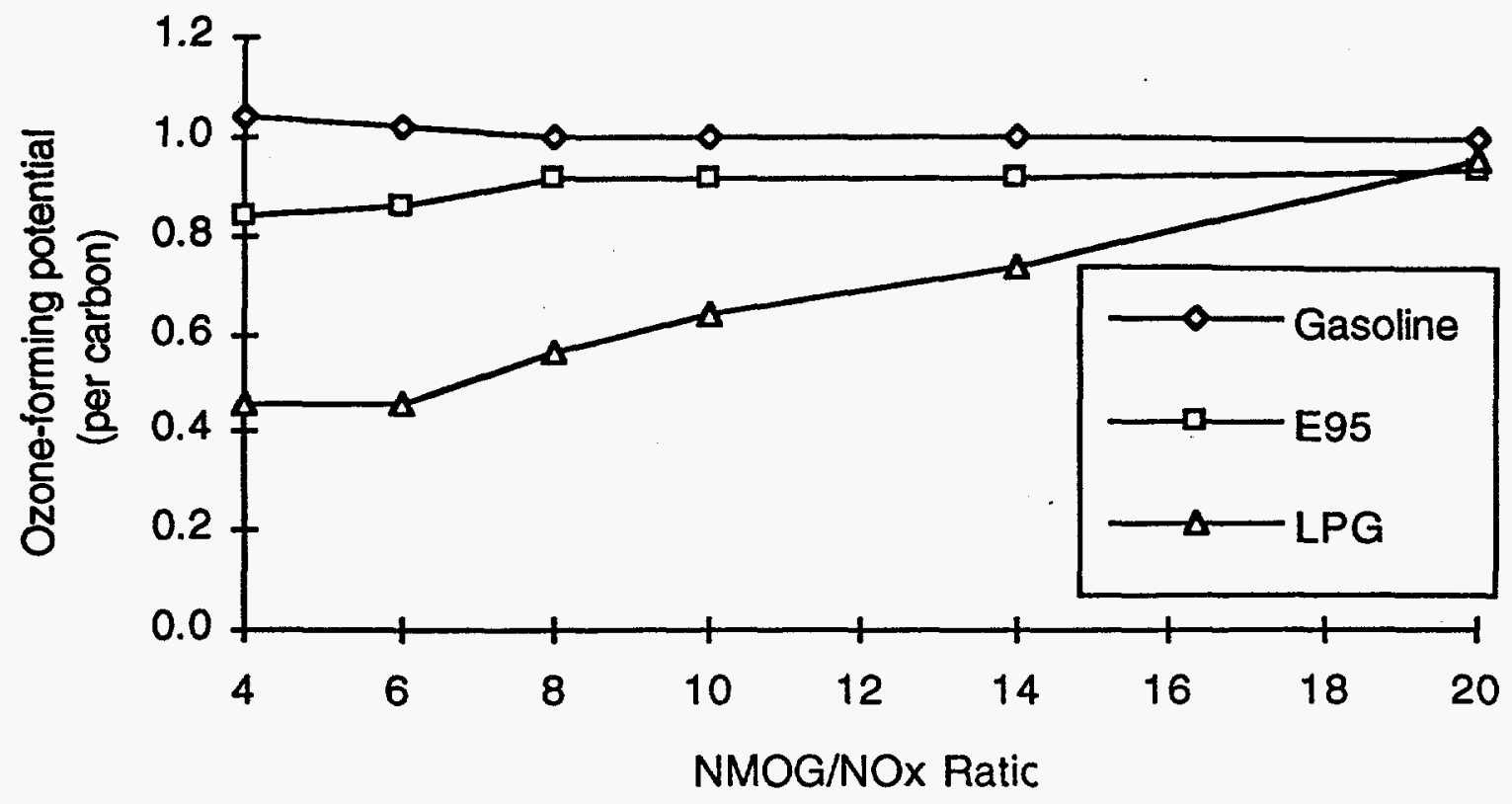

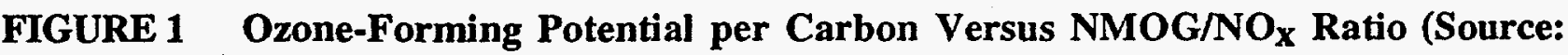
Reference 11) 